\title{
GT2016-56123
}

\section{ULTRA LOW EMISSION TECHNOLOGY INNOVATIONS FOR MID-CENTURY AIRCRAFT TURBINE ENGINES}

\author{
Tomas Grönstedt \\ Chalmers University of Technology \\ Göteborg, Sweden \\ Andrew Rolt \\ Cranfield University \\ Cranfield, United Kingdom \\ Kyros Yakinthos \\ Aristotle University of Thessaloniki \\ Thessaloniki, Greece \\ Nicholas Tantot \\ SNECMA \\ Moissy-Cramayel, France
}

\author{
Carlos Xisto \\ Chalmers University of Technology \\ Göteborg, Sweden \\ Nicolás García Rosa \\ Institut Supérieur de l'Aéronautique \\ et de l'Espace \\ Toulouse, France \\ Stefan Donnerhack \\ MTU Aero Engines AG \\ Munich, Germany \\ Oliver Schmitz \\ ARTTIC \\ Munich, Germany
}

\author{
Vishal Sethi \\ Cranfield University \\ Cranfield, United Kingdom \\ Arne Seitz \\ Bauhaus Luftfahrt, e.V. \\ Ottobrunn, Germany \\ Paul Newton \\ Rolls-Royce plc \\ Derby, United Kingdom \\ Anders Lundbladh \\ GKN Aerospace \\ Trollhättan Sweden, Sweden
}

\begin{abstract}
Commercial transport fuel efficiency has improved dramatically since the early 1950s. In the coming decades the ubiquitous turbofan powered tube and wing aircraft configuration will be challenged by diminishing returns on investment with regards to fuel efficiency. From the engine perspective two routes to radically improved fuel efficiency are being explored; ultra-efficient low pressure systems and ultraefficient core concepts. The first route is characterized by the development of geared and open rotor engine architectures but also configurations where potential synergies between engine and aircraft installations are exploited. For the second route, disruptive technologies such as intercooling, intercooling and recuperation, constant volume combustion as well as novel high temperature materials for ultra-high pressure ratio engines are being considered. This paper describes a recently launched European research effort to explore and develop synergistic combinations of radical technologies to TRL2. The combinations are integrated into optimized engine concepts promising to deliver ultra-low emission engines. The paper discusses a structured technique to combine disruptive technologies and proposes a simple means to quantitatively screen engine concepts at an early stage of analysis. An evaluation platform for multidisciplinary optimization and scenario evaluation of radical engine concepts is outlined.
\end{abstract}

\section{INTRODUCTION}

Since 1971 revenue passenger kilometers (RPK) have grown by $6.5 \%$ per annum $[2,3]$. In the same time frame $\mathrm{CO}_{2}$ emissions from aviation have increased yearly by $2.25 \%[3,4]$. This is similar to the growth of world carbon emissions from fuel combustion and cement manufacture, for which the pace is about $2.1 \%[5,6]$. Aviation is thus characterized both by a remarkable pace of fuel efficiency improvement as well as an exceptional rate of growth.

In Europe, ambitious goals to curb $\mathrm{CO}_{2}$ emissions from aviation are proposed. In a Strategic Research and Innovation Agenda (SRIA 2050), a $75 \%$ reduction to year 2050 relative to a year 2000 reference is outlined [7]. This revolution in $\mathrm{CO}_{2}$ emissions should be achieved while fulfilling a $90 \% \mathrm{NO}_{\mathrm{x}}$ and a $65 \%$ perceived noise reduction.

Reaching a $75 \%$ reduction in $\mathrm{CO}_{2}$ generation is a formidable challenge that opens for several routes of realization. The SRIA 2050 does not specify how the $\mathrm{CO}_{2}$ reduction contributions will be distributed between engine and airframe, only that a $68 \%$ total efficiency is targeted. The 2050 scenario explored here envisions an ultra-efficient engine with a revolutionary core installed on an advanced tube and wing aircraft. Recent studies using advanced tube and wing concepts have shown impressive fuel efficiency improvements with far less advanced core engines. Boeing estimated a 54\% fuel burn reduction with a truss braced high aspect ratio wing concept "SUGAR High" using an advanced but relatively conventional engine [8]. MIT's double bubble lifting body concept features an advanced high aspect ratio wing targeting close to a $71 \%$ reduction in fuel burn. This concept also used an advanced engine concept with a conventional architecture core $[8,9]$. 


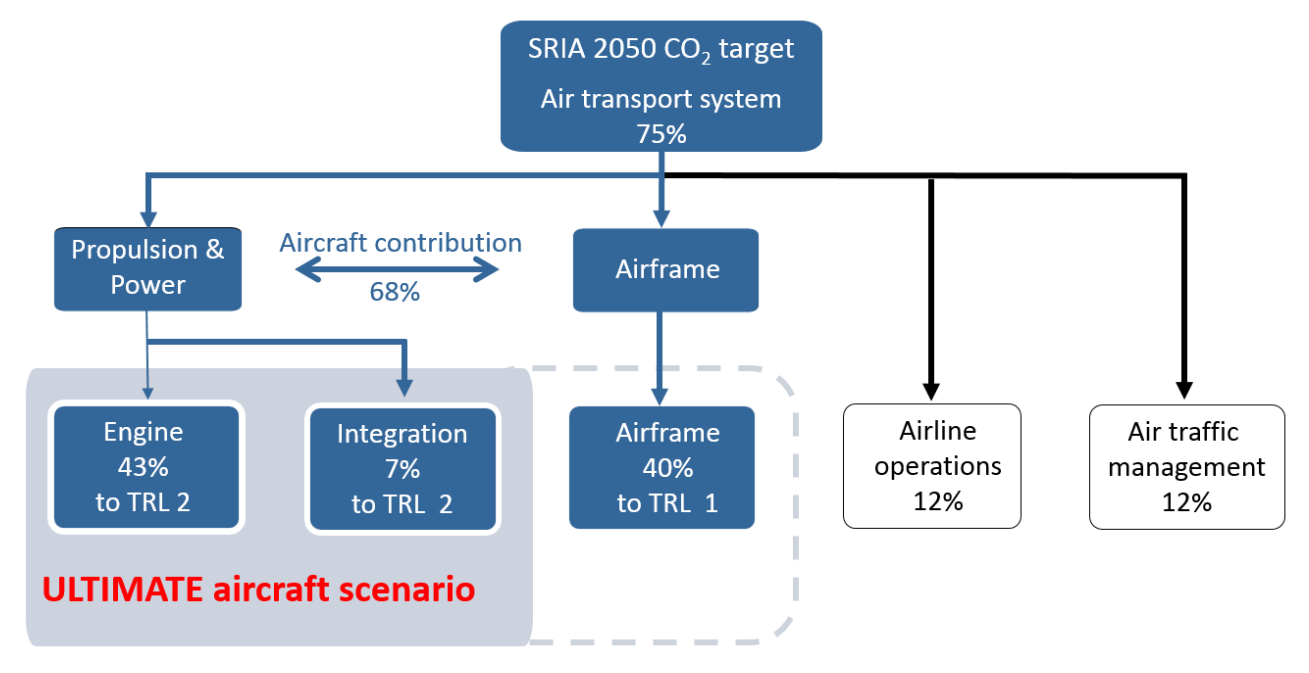

FIGURE 1. ULTIMATE ROUTE TO REALISING THE SRIA 2050 TARGETS

The breakdown of the SRIA 2050 targets proposed for the ULTIMATE scenario outlined herein is summarized in Figure 1. It should also be pointed out that the developed ultra efficient cores are applicable to almost any year 2050 aircraft and propulsion system scenario such as blended wing body concepts, horizontal double bubble, Prandtl joined-wing concepts, turboelectric and hybrid propulsion concepts.

Despite the outstanding improvements that have been achieved since the introduction of the first gas turbine turbofans, there are still significant sources of inefficiency in propulsion systems that could be addressed. Long range, state of the art turbofans typically generate propulsion thrust with an overall efficiency of around $40 \%$. Significant improvement in propulsion system efficiency is therefore theoretically possible.

As will be discussed in more detail, the major losses sources occurring in state-of-the art turbofan engines are combustor irreversibility, core exhaust thermal losses and unused kinetic energy in the bypass flow. On-going aero engine research is well underway to reducing the amount of unused kinetic energy in the bypass through the introduction of advanced geared and open rotor concepts. To systematically explore radical solutions for reducing combustor irreversibility and core exhaust thermal losses an EC funded research project "Ultra Low emission Technology Innovations for Mid-century Aircraft Turbine Engines" (ULTIMATE) has been initiated.

The ULTIMATE project, scheduled for 2015-2018, will develop ultra efficient powerplant concepts up to TRL 2 as a joint undertaking between four of the largest engine manufacturers in Europe; Rolls-Royce (UK), MTU Aero Engines (Germany), SNECMA (France), GKN aerospace (Sweden), the four universities Chalmers University (Sweden), Cranfield University (UK), Aristotle University of Thessaloniki (Greece), Institut supérieur de l'aéronautique et de l'espace (France), the research institute Bauhaus Luftfahrt as well as the technology management company ARTTIC.
This paper is devoted to presenting a number of radical engine concepts combining disruptive propulsion technologies aiming for the SRIA 2050 targets. The technologies are presented in a framework allowing a systematic search for ultra-low emission engines. The paper also discusses how to quantitatively screen technologies at an early project phase and describes a multidisciplinary optimization platform used to further investigate the down-selected concepts.

\section{ULTRA LOW EMISSION ENGINES}

A lost work potential, previously described in [10], has been used to evaluate the cruise performance of a fictitious state-ofthe-art turbofan engine. The terms have broadly been distributed onto its components as shown in Figure 2. The performance assumptions needed are provided in the Appendix of this paper. The data have been chosen to represent a year 2015 long range turbofan engine.

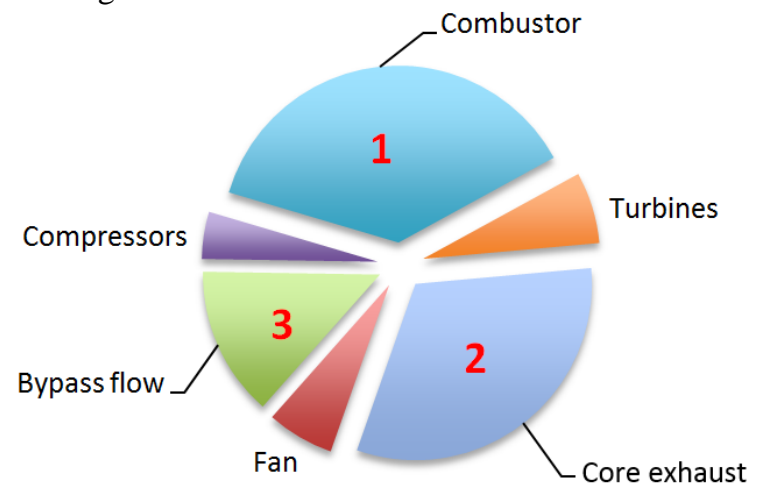

FIGURE 2. DISTRIBUTION OF LOST WORK POTENTIAL IN A STATE OF THE ART TURBOFAN 


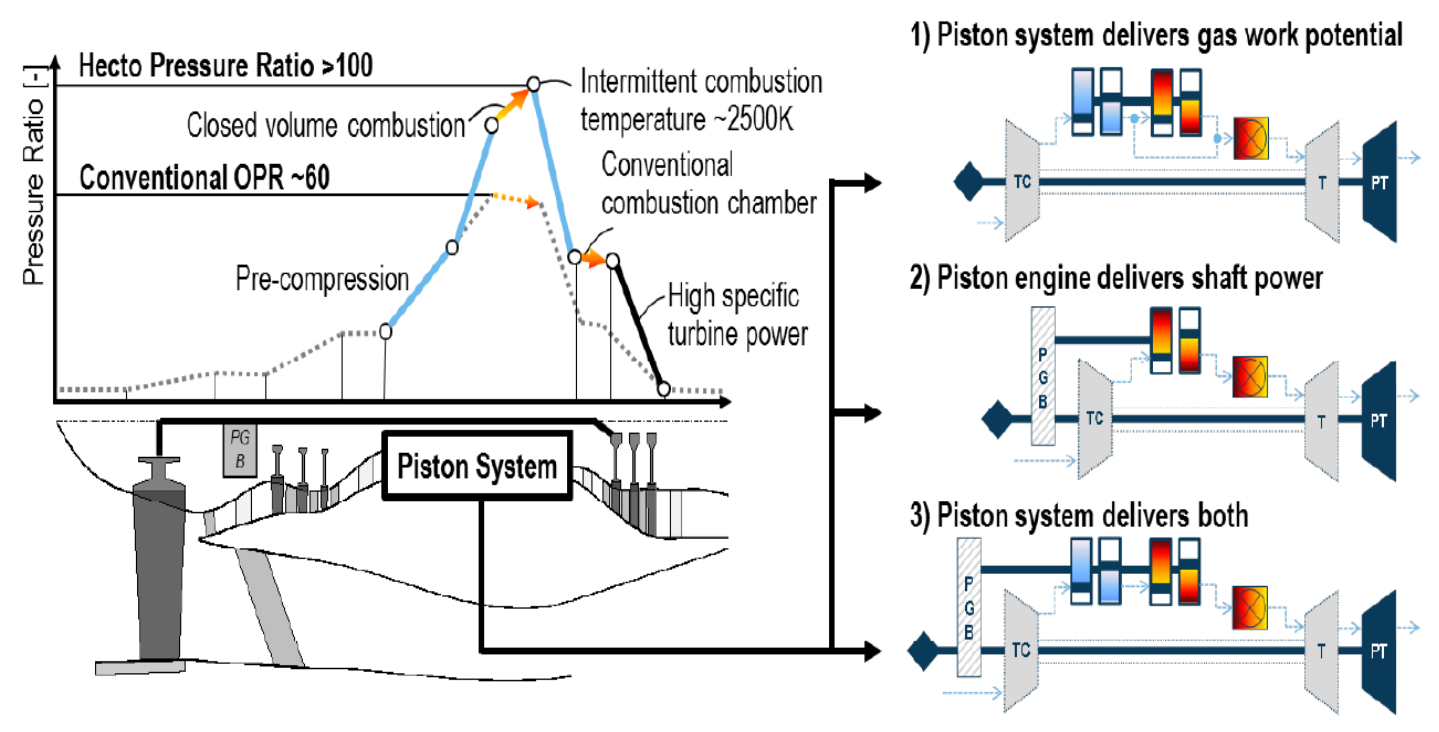

FIGURE 3A. PISTON BASED “COMPOSITE CYCLE” REALIZATION OPTIONS [11]

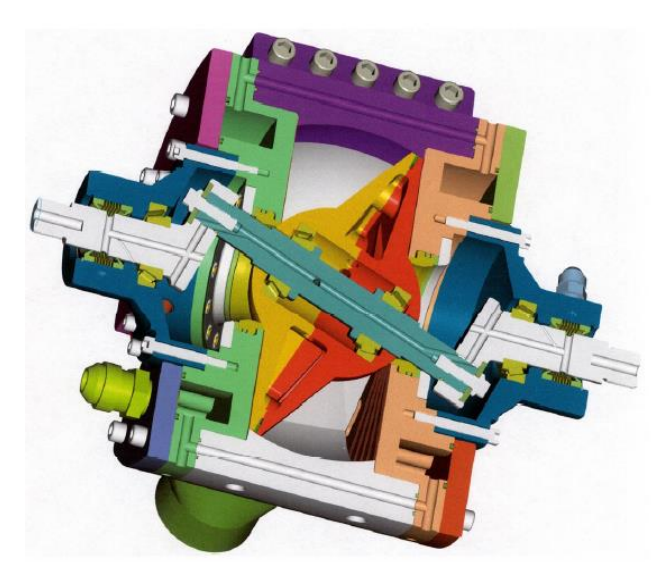

FIGURE 3B. NUTATING DISC COMPONENT [12]

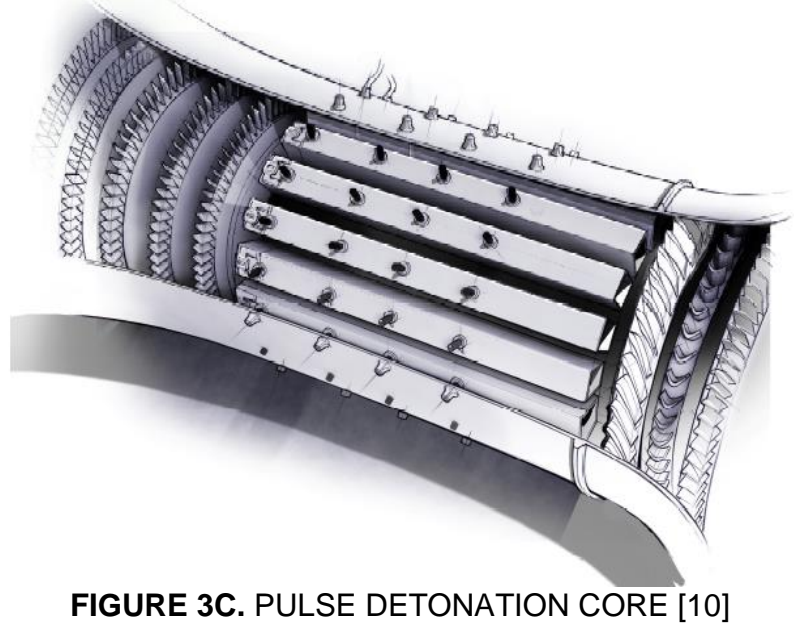

FIGURE 3C. PULSE DETONATION CORE [10]

FIGURE 3. ULTIMATE CONCEPTS ATTACKING LOSS SOURCE 1 (COMBUSTOR)

From Figure 2 it can be observed that the "Fan", the "Compressors" and the "Turbines" components together represent a substantial portion of irreversibility. However, the dominating sources are originating from the 1) "Combustor", the 2) "Core exhaust" and the 3) "Bypass flow".

The "Core exhaust" loss consists primarily of unused thermal and kinetic energy exiting the core. The "Bypass flow" component includes bypass duct and nozzle pressure losses, as well as residual thermal and kinetic energy in the bypass exhaust stream.

Current aero engine propulsor research and development is in the process of radically increasing propulsive efficiency through the introduction of advanced geared and open rotor concepts attacking the "Bypass flow" loss source. Rather than to try to contribute to reducing the ever decreasing loss sources "Fan", "Compressors" and "Turbines", the focus is now set on the dominant "Combustor" and "Core exhaust" loss sources, and attention will be given to propulsor technologies and the related propulsive efficiency ("Bypass flow") by identifying and discussing key enabling technologies.

\section{The big three}

To identify technologies that allow attacking the major loss sources, a more elaborate discussion of "the big three" loss sources are called for.

1. Combustor loss (source 1): Adding heat through internal combustion will always generate considerable entropy. 


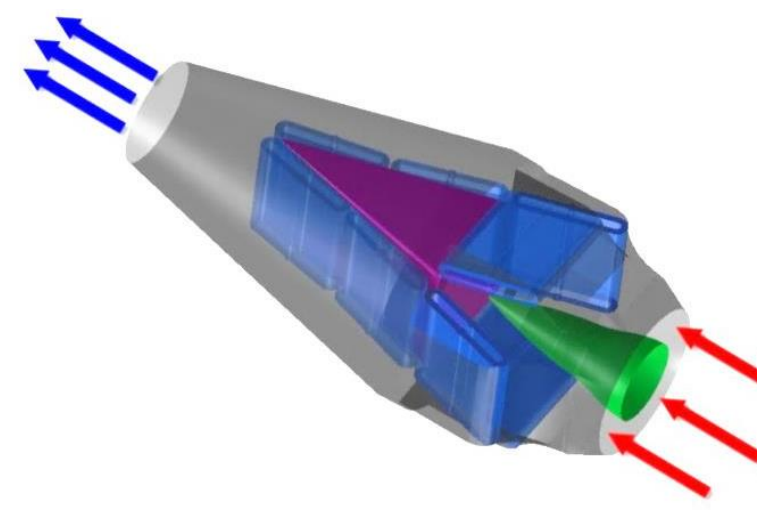

FIGURE 4A. RECUPERATOR CONCEPTUAL DESIGN

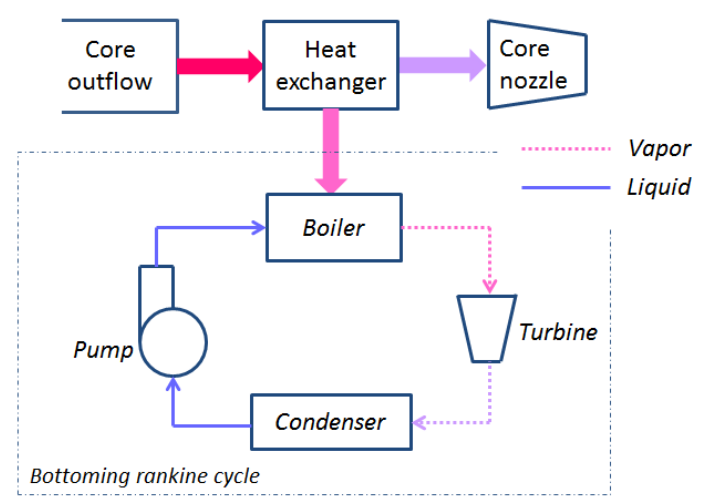

FIGURE 4B. BOTTOMING RANKINE CYCLE CONCEPT [13]
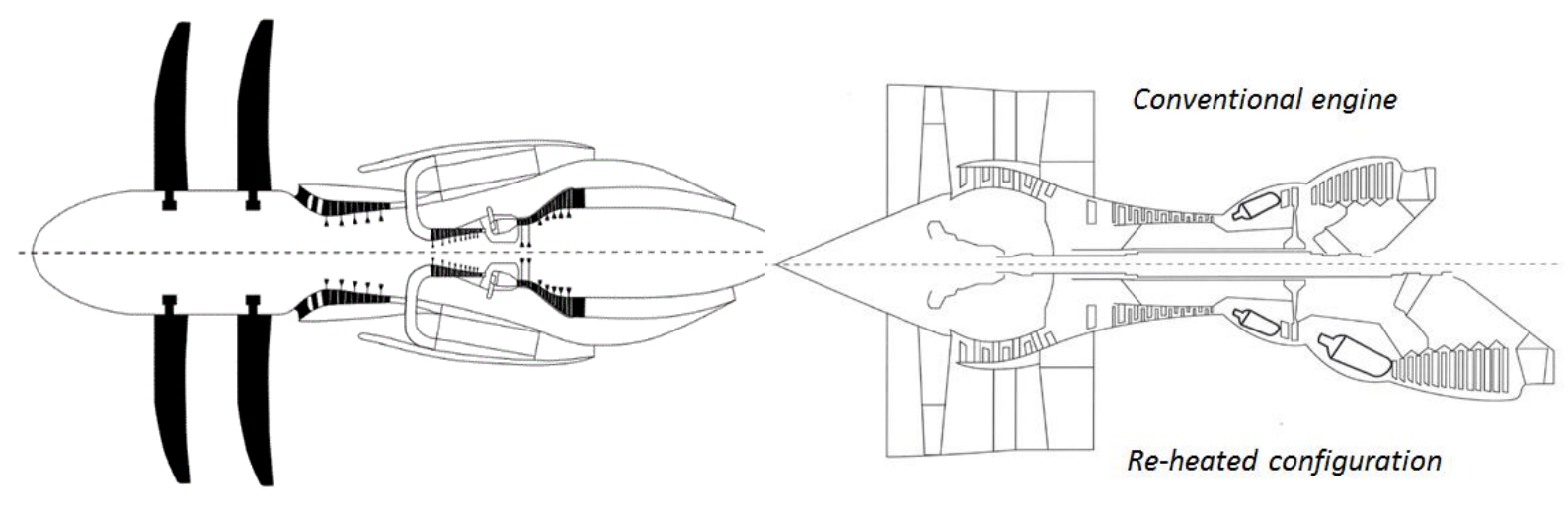

FIGURE 4C. INTERCOOLER INTEGRATION

FIGURE 4D. REHEAT INTEGRATION

(ENABLER

FIGURE 4. ULTIMATE CONCEPTS ATTACKING LOSS SOURCE 2 (CORE EXHAUST)

However, the state-of-the-art constant pressure type of combustion process (associated with $3-4 \%$ pressure drop) introduces unnecessarily high levels of irreversibility. The alternative of a constant volume combustion process gives a pressure rise, with the potential to substantially reduce the entropy increase needed for the temperature rise.

2. Core exhaust loss (source 2): The "Core exhaust" loss is primarily due to thermal energy lost to the surroundings, although some excess kinetic energy and fluid friction associated pressure losses contribute as well.

A modern turbofan engine may run with a cruise core exhaust of $800 \mathrm{~K}$, which gives significant potential for energy recovery considering that the ambient temperature is about $600 \mathrm{~K}$ lower. Recovered heat may either be recuperated back into the cycle or captured by a secondary cycle. Recuperation would incur some additional irreversibility through pressure losses and finite temperature difference heat transfer. For a secondary cycle thermodynamic limitations, pressure and heat transfer associated losses will reduce the potential to convert the exhaust heat into useful power. Nevertheless, it is worth exploring solutions that have the potential to recover large parts of the "Core exhaust" losses through a dedicated technology.

3. Bypass flow loss (source 3): The "Bypass flow" loss is associated primarily with excess kinetic energy lost in the bypass jet, but also with fluid friction losses in the fan, bypass duct and the bypass nozzle. Radically reducing the excess kinetic energy is possible by increasing engine mass flow and reducing exhaust jet velocities (reducing specific thrust). Considerable research and development effort is being spent to introduce advanced geared and open rotor propulsors promising to recover a large part of these losses. Still, further research is needed to provide breakthrough technologies to enable capturing as large part of the loss source as possible. To maximise the benefit for the radical technologies targeting the "Combustor" and "Core exhaust" losses, a greater degree of flexibility with respect to operability and variability is also expected to be needed, 


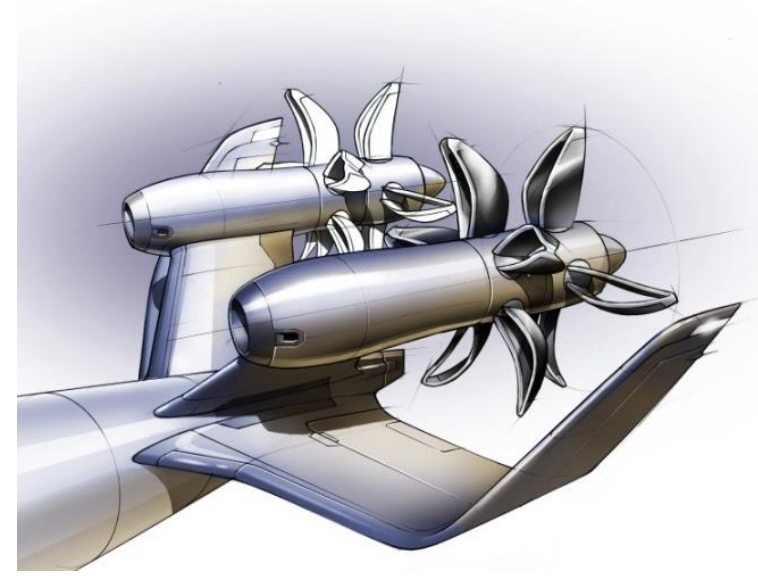

FIGURE 5A. BOX-PROP OPEN ROTOR PROPELLER CONCEPT [14]

compared to propulsor technologies integrated on a conventional aero engine.

\section{ULTIMATE TECHNOLOGIES}

Technologies attacking the “Combustor" loss (source 1): A breakthrough reduction in the combustor component loss can be achieved by exploiting a constant volume type of process rather than the constant pressure process used in a state-of-theart turbofan. Three technologies that might provide this benefit are: piston engine technology (Figure 3A), nutating disc technology (Figure 3B) and pulse detonation technology (Figure 3C).

Piston engines, in particular Otto and Diesel types, constitute the most successful class of non-Brayton cycle machines, being in service in ground-based, naval and aeronautical applications. Until the adoption of Brayton cycle based jet engines in the 1950s, piston engines were the prevailing aero engine type with unmatched thermal efficiency levels comparable even with modern gas-turbine technology. Based on the Seiliger cycle process, piston engines allow for higher peak pressure and temperature levels and feature (partial) constant volume combustion, thus achieving higher efficiency than engines based on the Brayton cycle. Gas-turbine engines based on the Brayton cycle, on the other hand, feature outstanding power densities and low mechanical complexity compared to traditional piston engines. Hence, combining the high pressure, high temperature pressure gain combustion capability of the piston technology with the specific power capability of the gas turbine cycle to form a piston topped "composite cycle" becomes very attractive.

The composite cycle provides new degrees of freedom for matching and operational tailoring. Figure 3A shows concepts delivering gas work potential (Type 1), shaft power (Type 2) and both gas work potential and shaft power (Type 3). Even very early composite engine realizations showed quite high efficiencies [16]. By utilizing today's advanced design, materials

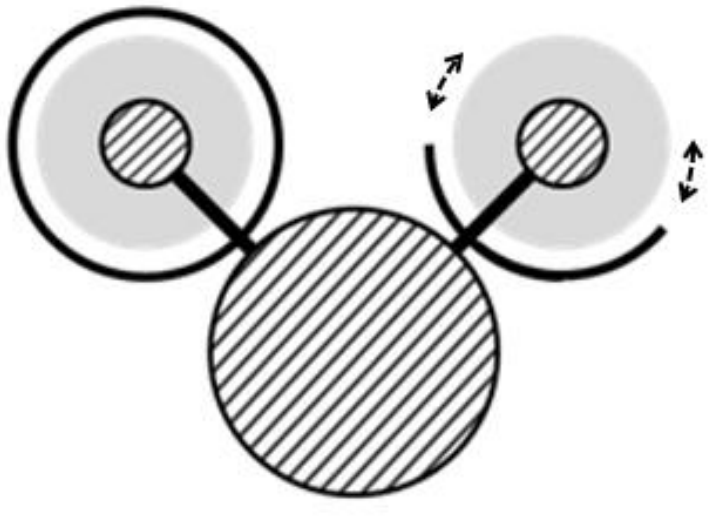

FIGURE 5B. CIRCUMFERENTIALLY RETRACTABLE NACELLE CONCEPT [15]

and manufacturing methods, substantially higher performance can be expected.

An alternative to the piston based composite technology is provided by the nutating disc concept illustrated in Figure $3 \mathrm{~B}$. The implementation is, in contrast to piston technology, a quite recent innovation [12]. Like the piston engine, this concept works on an intermittent combustion cycle. The key component, the disc, is mounted at an angle to a Z-shaped shaft. As the shaft rotates on its vertical axis, it internally twists the disk, so that the disk performs a nutating (wobbling) motion without rotating in the direction of the shaft. The motion is similar to the periodic motion of a coin wobbling on a flat surface. A major advantage of the nutating engine is that each side of the disk is used once per engine revolution promising to provide a low weight constant volume based combustion solution. The nutating motion is also associated with a relatively low levels of vibration. Having been developed and tested for a UAV engine, the concept is hoped to provide a low vibration, high efficiency and highly compact solution. The three variants proposed for the piston topped composite cycle, as presented in Figure 3A, are equally of interest with the nutating disc topped concept. In addition, both composite engine types may benefit from intercooling and/or the addition of a second (constant pressure) combustor, with the potential benefits of increased specific power, increased thermal efficiency and reduced emissions. Apart from architectural arrangements, key technology challenges involve the aerothermodynamic interaction of the piston and turbo components, and engine rating and part power optimization and maintaining an efficient ultra-low emission combustion processes.

The proposed implementation of the pulse detonation core concept [10] differs from the two reciprocating concepts by not requiring the additional conventional combustor in order to reach the high temperatures of a gas turbine. The concept also promises to recover some of the dynamic energy generated during the detonation waves, theoretically outperforming the two other constant volume combustor concepts. Key technology 
challenges consist of the the aero-thermodynamic interaction of the detonation waves and turbo components, integration of compression intercooling to reduce risk of auto-ignition and to ensure efficient part power operation.

For all three combustor technologies the dynamic combustion process and shorter residence times are expected to contribute to reduced $\mathrm{NO}_{\mathrm{x}}$ production. In conjunction with the greatly reduced fuel burn being targeted the technologies may be designed to deliver the $90 \%$ SRIA $2050 \mathrm{NO}_{\mathrm{x}}$ reduction target. If not, it is expected that some cycle limitations will be needed. The necessary cycle limitation can be achieved by limiting the combustor entry and flame temperatures. In turn, this can be achieved by dropping cycle pressure ratio, or by using intercooling. A third option is to use a reheat combustor which allows both combustors to run at substantially lower peak temperatures.

Technologies attacking the "Core exhaust" loss (source 2): A breakthrough reduction in core exhaust component losses can be achieved by technologies that substantially reduce the exit temperature in comparison with a state-of-the-art turbofan. Three technologies that could achieve this are recuperation (Figure 4A), Rankine bottoming (Figure 4B) as well as intercooling (Figure 4C).

Recuperation reduces the core nozzle exit temperature through the recovery of core exhaust heat being returned to preheat the air prior to combustion. A well-known radical concept that provides synergy with the recuperator is the use of an intercooler $[17,18]$. A freer optimization exploring the use of alternative types of heat exchangers and different installation locations would allow further fuel burn potential to be established for the technology. Synergies with composite piston topping could also provide benefits. As a more radical approach, integration with heat transfer systems using a secondary fluid system [19], as well as integration with inter-turbine reheat may be considered.

The Rankine bottoming cycle technology reduces the core nozzle exit temperature by extracting heat from the core flow (Figure 4B). The extracted heat is used to heat a fluid within a secondary fluid system which is used to generate additional power. Combining a Rankine bottoming cycle with a topping gas turbine has been a successful way to reach unrivalled efficiency in stationary power generation. The concept of using Rankine bottoming for flight application has recently received attention for aero engine application [13]. Key research tasks are to develop and optimize the secondary system with respect to design and integration aspects of the bottoming cycle components, to assess part load performance and to explore the use of different secondary fluids. In particular, synergies with intercooling and composite topping technology promises to provide fuel burn benefits.

Intercooling is an enabler to high overall pressure ratio engines. For a fixed combustor exit temperature, this increase in pressure ratio then leads to a reduced core nozzle exit temperature. Hence intercooling can be seen as a concept that indirectly captures exhaust heat. On the other hand, it may also serve as a concept that can be optimized to decrease compressor exhaust temperature and allow for increased energy input from a recuperator. Further, it could serve as an enabler for very high bypass ratio engines by decreasing power requirement during compression. This would allow a smaller core to drive a fan/propulsor. Intercooling also promises to integrate well with piston-, nutating- and pulse detonation composite topping technologies. In addition, intercooling reduces compressor exit temperature and hence combustor entry temperature, which in general reduces $\mathrm{NO}_{x}$ emissions.

Key intercooling technology aspects are to develop designs that make full use of the synergistic benefits with other ULTIMATE technologies. The technology can also be used to explore radical installation concepts such as a split flow first stage compressor blade. Such a configuration would allow producing the intercooler coolant flow for an open rotor pusher configuration. It could also be integrated into an open rotor tractor configuration as illustrated in Figure 4C, or into a configuration with an ultra-high overall pressure ratio (> 150).

Another concept that provides interesting potential for synergy is inter-turbine reheat (illustrated in Figure 4D). Reheat has been successfully used by Alstom in its GT24 and GT26 industrial gas turbine engines. Sequential combustion facilitates a gas turbine with a significantly higher power density than conventional cycles [20] and is expected to integrate well with bottoming engine technologies such as recuperation and Rankine bottoming. By allowing another degree of freedom in terms of introducing heat into the engine the maximum combustor temperature can be kept down which supports a drastic reduction in $\mathrm{NO}_{\mathrm{x}}$ generation. In addition the reheat concept will increase core specific power which allows for weight reduction and ultra-high bypass ratios. Breakthrough materials such as ceramic matrix composite materials (such as $\mathrm{SiC}$ ) should be used to minimize cooling requirements for the second combustor and would be a key technology enabler for its success

Technologies attacking the "Bypass flow" loss (source 3): A large part of the reduction of this loss source, as needed to achieve the SRIA 2050 targets, is expected from the use of advanced powerplant architectures targeting ultra-high propulsive efficiency. In the scenarios outlined here, this comprises an advanced geared turbofan engine for long range missions and an open rotor concept primarily targeting short and medium range missions. These engine architectures are already at high TRL levels and will only be modelled to support the radical core concepts being explored. In addition to this propulsion plant modelling effort, a number of advanced technologies supporting the integration of the cores are planned to be modelled.The technologies attacking the "Bypass flow" loss thus serve a two-fold purpose:

1. Provide a propulsor platform on to which the core technologies attacking the "Combustor" and "Core exhaust" losses can be integrated and optimized.

2. Provide radical enabling technology that will allow further reduction of the "Bypass flow" loss and have the potential to radically reduce noise. 
Integration technologies to be explored cover: ultra-thin adaptive inlet and adaptive external shapes, circumferentially retractable concepts as illustrated in Figure 5B. Means to provide variable fan flow capacity and operability using variable pitch fan rotors, variable bypass and core nozzles and variable inlet guide vanes as well as means to provide open rotor variability including advanced blade actuation systems and pitch control mechanisms.

In addition, a box-blade open rotor propeller concept, as illustrated in Figure 5, allowing a forward swept first rotor and maximum rotor separation for noise reduction will be optimized as part of the project.

\section{The Advanced Tube and Wing configurations}

The ULTIMATE engine configurations will be integrated and evaluated on an advanced tube and wing (ATW) year 2050 aircraft platform. The long range intercontinental and the short range intra-European ATW concepts will be defined by exploring:

- Aerodynamics: advanced very flexible slender in-plane wing; exploitation of passive or hybrid laminar flow on wing, empennage, forward fuselage and nacelles, riblets on the fuselage surface and shock contour bumps on wing upper surface.

- Structures: Omnidirectional ply orientation according to the primary stress distribution; Nano-technologies with greatly reduced density and superior strength properties; geodesic fuselage design; advanced bonding; variable camber and cant control on wing; foldable wing concepts and adaptive structures applied to the engine cowl for optimising propulsion system performance within the operating envelope.

- Systems: introduction of a fuel-cell to serve as an auxiliary power generation device; and, wholesale application of a solely Direct Current (DC) power transmission architecture.

\section{ATW and competing 2050 aircraft configurations}

A year 2050 tube and wing aircraft is expected to be lightweight, allow a scalable design, and provide a high level of flight safety and maintainability. Moreover it has been shown to have a very large potential for further reduction of energy consumption from aerodynamic and structural improvement [21].

Previous and on-going studies, such as the Boeing X-48, the Silent Aircraft Initiative, the various studies in NASA's Future Aircraft $(\mathrm{N}+3)$ and the European NACRE research, have investigated the efficiency improvement potential from radically new aircraft configurations, such as:

- Blended wing body configurations

- Horizontal double bubble configurations

- Prandtl joined-wing configurations
The blended wing body is a flying wing with an expanded centre section for the payload, which promises to reduce the wetted area and thus drag by around $20 \%$. The configuration also potentially allows internal integration of the propulsion, ingesting a large part of the boundary layer air for further energy efficiency gain. To house a passenger compartment in a reasonable aerofoil thickness, less than e.g. 15-20\% of the chord, the aircraft must be very large, typically above 500 seats.

The horizontal double bubble is a fuselage with two threequarter circular cross section pressure tubes laid side by side, to achieve a wide passenger cabin for aircraft of around 100-200 seats. The greater packing density and ability to integrate fuselage boundary layer ingestion with tail mounted turbofans can reduce weight and drag by up to $15 \%$.

The Prandtl joined wing [22] replaces the horizontal and vertical tail with a forward swept second wing, which is connected to the first, rearward swept wing via vertical winglets. This configuration minimizes induced drag and is mechanically robust allowing use of thin wing sections, resulting in up to $15 \%$ reduction in drag.

However, parallel studies, have shown that more conventional looking aircraft with an advanced tube and wing (ATW) configuration allow similar, large reductions in energy needs, by employing new materials, subsystems and advanced engines. This result stems from the fact that the radical configurations, while on the surface slightly better aerodynamically, must compromise on flight controls, from e.g. shorter moment arms, compatibility between pressure vessel and external aerodynamic shapes and transonic drag rise from thick root aerofoils. The radical configurations are also not as scalable as the tube and wing concept, and some are only realistically applicable to the largest size of aircraft. Furthermore, drag reductions that some of these configurations show from internal engines and power saving boundary layer ingestion, is costly in terms of lost modularity, engine access for maintenance as well as fan aerodynamical and aeroelasticity issues. Similarly the turbo electric and battery electric propulsion modes require very large increases in power and energy density to be viable for main propulsive use in aircraft. Aircraft fuel is currently 50-100 times more power dense than batteries, and the historical improvement rate of 2-3\% makes it uncertain whether they will reach the level of power density necessary to play a major role for reaching the SRIA 2050 targets.

Irrespective of which aircraft engine scenario(s) that will play an important role in the future, an ultra-efficient core engine will provide a much needed benefit necessary to reach the SRIA 2050 targets. Such advances would be directly applicable to propulsion systems envisioned for radical aircraft configurations such as blended wing body concepts, horizontal double bubble and Prandtl joined-wing concepts. Likewise, such concepts would provide an almost direct applicability to providing ultraefficient core engines for turbo-electric and hybrid propulsion as well as for hydrogen, methane and biofuel propelled concepts. 


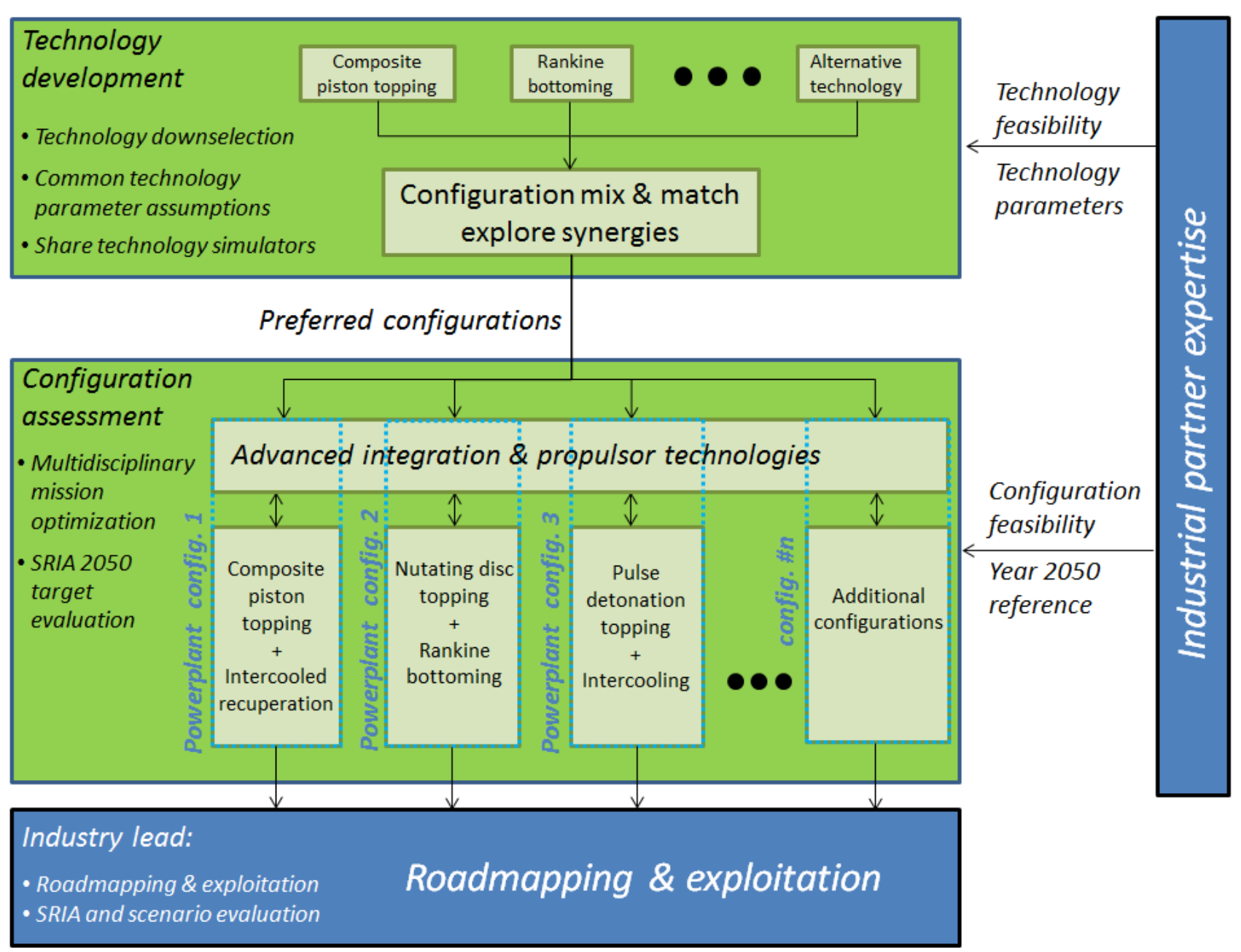

FIGURE 6. ULTIMATE TECHNOLOGY SCREENING AND DEVELOPMENT PROCESS

\section{THE SEARCH FOR ULTRA LOW EMISSION ENGINES}

The down-selection of propulsion technologies is challenging for a number of reasons:

- a large number of disruptive technologies exist

- most technologies can be configured in several ways depending on powerplant architecture and on which other technology it is combined with

- a multitude of synergistic combinations of technologies can be defined

Due to the stated complexity a two stage process, illustrated in Figure 6, is proposed for downselecting the preferred powerplants:

1. A technology development phase leading to a limited number of preferred powerplant configurations (3-5 configurations). A simplified partially quantitative selection metric is proposed for this stage.

2. An optimization phase making configuration assessments towards the full 2050 SRIA targets
In the past propulsion technology down-selection has been performed using Quality Function Deployment (QFD). This approach was used for the NASA N+3 propulsion technologies review process [8]. As stated in this work the downside to the QFD was that it did not capture the interdependence between the technologies. This inability to capture interdependencies is particularly detrimental for the research task singled out here, i.e. to combine radical core technologies making maximum use of synergies. Consider for example the use of intercooling. On a long range mission intercooling could provide around 5\% fuel burn reduction [23]. This may be rendered insufficient to reach the SRIA 2050 targets and hence be considered as an unsuitable technology to attack the core exhaust loss. However, when integrated with piston topping intercooling could improve the impact of the piston topping substantially. This would originate from that the share of piston topping and hence constant volume combustion could be increased as the intercooler reduces the combustor inlet temperature. Furthermore, a potential benefit of intercooling is that it works as an enabler to achieve high overall pressure ratio cycles. Unfortunately, the efficiency improvement rate levels off with increasing pressure ratios in a Brayton cycle. 
With incorporation of piston topping this trend may shift to a more favorable one, hence increasing the advantages provided by intercooling. Such a mutual synergy may change the decision on the preferred powerplants completely and must therefore be captured early in the down-selection process. To accomplish this, a partially quantitative metric is proposed for the down-selection of the preferred powerplant configurations. Before this metric is defined, the work process will first be described in somewhat more detail.

The technology development phase, as illustrated in Figure 6 , will concentrate on model building, powerplant configuration pre-studies and technology down-selection. Model building refers to defining conceptual design tools for the ULTIMATE technologies allowing initial year 2050 assessments. The process will be supported by industry input on expected technology parameters such as material temperature capabilities, turbomachinery efficiencies etc. Simultaneously initial year 2050 powerplant and aircraft definitions will be setup along with year 2000 reference configurations.

Each technology attacking loss source 1 ("Combustor") can be configured with several alternative technologies attacking loss source 2 ("Core exhaust"), and must allow successful optimization with the advanced propulsor and integration technologies (Loss source 3 - "Bypass duct"). To allow partners to freely explore synergies with other technologies (configuration $\mathrm{mix}$ and match), technology simulators comprising the key conceptual design process of the technologies will be developed and shared among the project partners.

\section{Quantitative metric for technology screening}

By establishing initial powerplant and aircraft definitions the cruise specific range of a particular configurations can be estimated:

$$
S R=a \frac{\mathrm{M} \frac{L}{D}}{S F C \cdot W}
$$

The specific range $(S R)$ captures the most critical system performance aspects of a configuration avoiding full mission analysis. An initial definition of the airframe will be accompanied by a cruise Mach number (M) an airframe weight $(W)$ and a lift over drag number $(L / D)$. This will allow estimates of added weight arising from the core technologies to be quantified against the relevant proportion, i.e. airframe weight. An initial cruise point propulsion system performance assessment will establish the $S F C$. For the particular research task of combining technologies attacking the major loss sources, it is viewed that this metric is the simplest sensible metric. It should be noted that ICAO proposed a metric derived from the specific range for their $\mathrm{CO}_{2}$ certification of new aircraft [24]. This metric uses a linear weighted combination of the inverse of the specific range measured in three operating points.
The cruise specific range parameter includes all the critical system parameters and keeps complexity down by limiting the assessment to a single vehicle operating point. The final downselection decision will be supported by qualitative $\mathrm{NO}_{\mathrm{x}}$ and noise assessments (better or worse) and industry advice on the feasibility of the powerplant. It is viewed that this approach strikes a balance between simplicity and accuracy, suitable for the screening of combinations of disruptive technologies to be studied.

As a next stage the preferred configurations will be carried over to the configuration assessment stage, see Figure 6, performing full mission evaluation, multidisciplinary design and optimization. The powerplants will be optimized for an intraEuropean and an intercontinental aircraft configuration by means of:

- an advanced multidisciplinary evaluation platform supporting the assessment against the SRIA 2050 targets

- an Advanced Tube and Wing aircraft model representative of year 2050 technology estimates

- a flexible work process allowing further powerplant configuration modifications

The flexible work process is needed since a number of aspects will be covered during the configuration assessment that was not covered in the technology development phase. For instance, a need redefining the preferred configuration to tailor the powerplant to the inter-continental or intra-European missions may arise (a technology may for instance show to be too heavy to obtain good performance for shorter missions). An existing technology may also need to be replaced to achieve better matching and synergy exploration, as evaluated for a whole mission (in contrast to the single point assessment of the technology development phase). Additionally, supporting technologies may need to be added, such as intercooling and inter-turbine burning, to boost the configuration to better meet the SRIA 2050 targets.

Finally, the work process will support the road-mapping $\boldsymbol{\&}$ exploitation of the developed ULTIMATE configurations by exploring them against a range of plausible scenarios of external forces. These include covering future fuel price development, environmental regulations and the robustness of the proposed conclusions against technology assumptions. Furthermore, it will be shown how the introduction of ULTIMATE technologies may affect air traffic, the air transport fleet energy need and overall environmental impact.

\section{ULTIMATE EVALUATION PLATFORM}

To develop and analyze the powerplant configurations against the SRIA 2050 targets, an evaluation platform is needed that can:

- $\quad$ support the definition of a year 2050 reference powerplant and aircraft configurations for the intra-European and intercontinental missions trajectories 


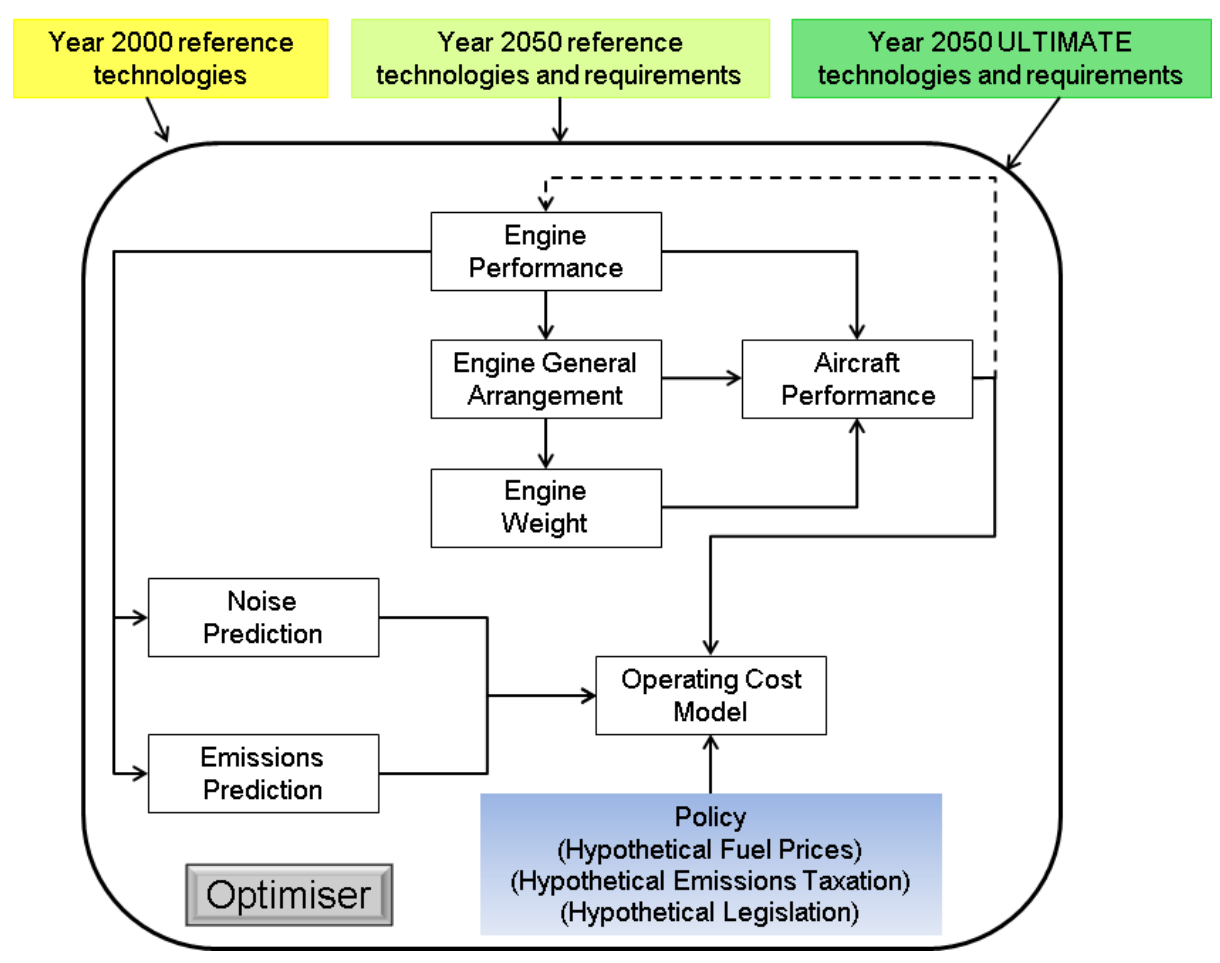

FIGURE 7: OVERALL STRUCTURE OF EVALUATION PLATFORM

- $\quad$ support the evaluation of flexible mission capability in terms of cruise altitude, variable speed and climb/descent

- allow for analysis that provides a break-down of the emission targets $\left(\mathrm{CO}_{2}, \mathrm{NO}_{\mathrm{x}}\right.$, noise $)$ into individual powerplant and airframe goals

- provide multidisciplinary optimization capabilities including design space exploration, parametric studies, sensitivity studies and trade-off studies

- support powerplant technology and top-level module requirements to be evaluated to TRL 2

- $\quad$ support analysing economic \& policy models and evolution of regulation

To provide analysis capabilities against these requirements, an evaluation platform will be defined; the Techno-economic Environmental Risk Assessment framework [25] adapted for year 2050 analysis (TERA2050). The overall structure of the evaluation platform is presented in Figure 7.

Within the EU collaborative projects VITAL, NEWAC and DREAM, a Techno-economic Environmental Risk Assessment framework was developed for a year 2020 set of requirements and inputs (TERA2020). This tool was developed, with the support of several leading European Universities (including Chalmers University, Stuttgart University, The Aristotle University of Thessaloniki, The National Technical University of Athens, ISAE and The Polytechnic University of Madrid) under the leadership of Cranfield University and was informed and influenced by several large OEMS including Airbus, GKN Aerospace, MTU Aero Engines Rolls-Royce Deutschland, Rolls-Royce UK and Snecma Moteurs. The evaluation platform will here be adapted to the year 2050 technology and powerplant projects to provide an evaluation platform for studied concepts. The following key evaluation modules are needed:

- Engine performance: to predict mission fuel burn and provide input data for the aircraft performance, the engine general arrangement prediction, powerplant weight, noise and emissions prediction [26, 27].

- Engine general arrangement: to determine basic engine dimensions and the gas path layout including component stage numbers, interface definitions, component lengths, etc. This will require estimating technology parameters for aerodynamics, material definitions such as temperature capabilities and mechanical properties. This module will provide input to the engine weight module as well as the aircraft performance module [26, 28].

- Engine weight: to predict engine component and whole engine weight from engine basic dimensions as provided by the Engine general arrangement module and year 2050 materials capabilities. This module will provide input to the aircraft performance module [28, 29].

- Aircraft performance: to serve as a platform for the year 2050 long range intercontinental and the short range intraEuropean technology configurations, as well as the year 2000 


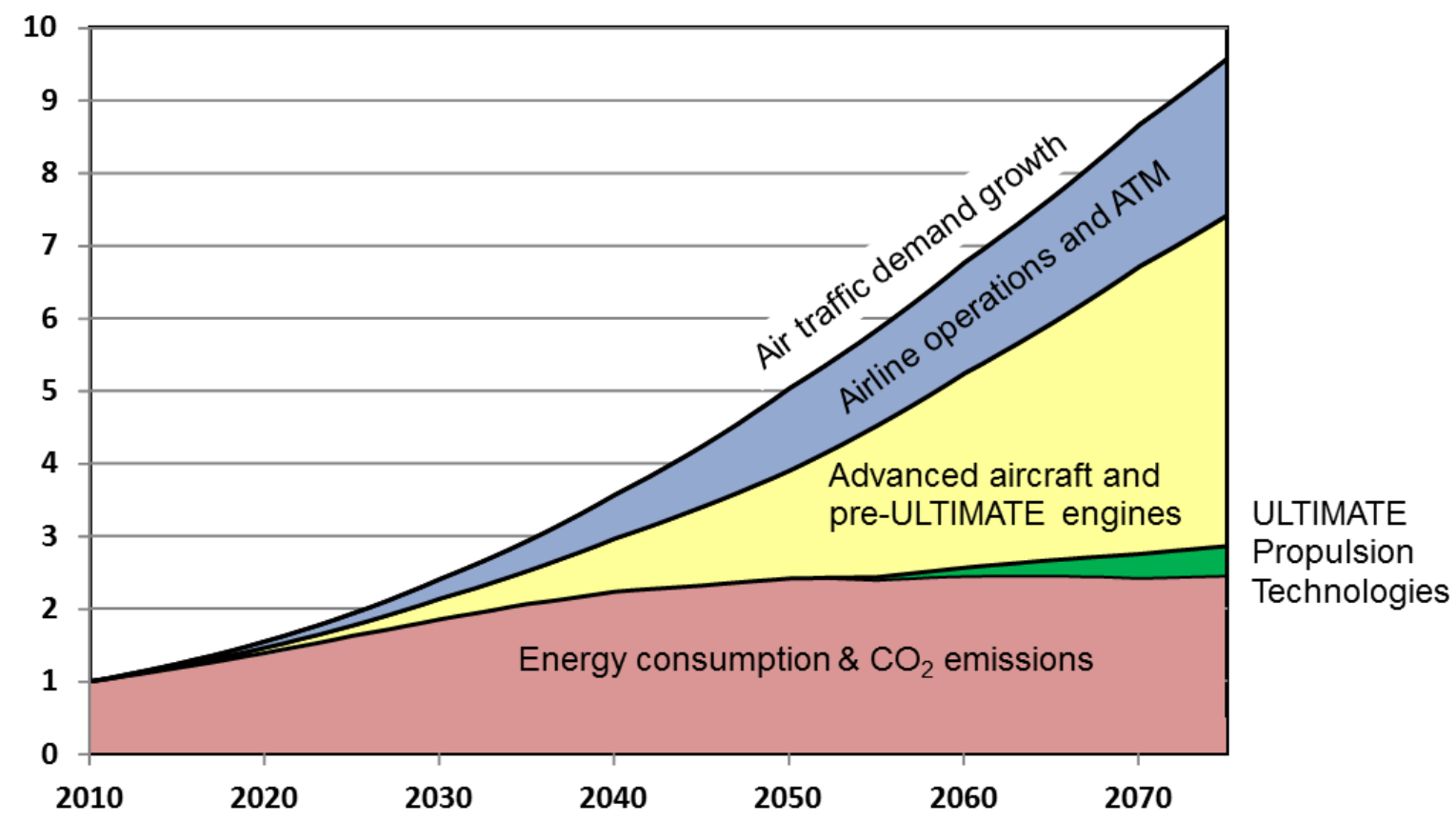

FIGURE 8: SCENARIO FOR ANNUAL GLOBAL CIVIL AVIATION FLEET CO2 EMISSIONS IN LINE WITH SRIA TARGETS, SHOWING THE POTENTIAL REDUCTION FROM ULTIMATE TECHNOLOGIES IF THERE WERE INTRODUCED TO ALL NEW AIRCRAFT FROM YEAR 2050 ONWARDS

reference configurations. The model will be set up for the assessment of aircraft-level improvements due to for instance advanced airframe aerodynamics and structures. This module will provide input to the operating cost module.

- Noise: to estimate noise emissions (EPNLdB) at the ICAO certification points (take-off, approach, flyby and sideline) by the use of the component based noise source modelling [28]. Based on modelling the Sound Pressure Levels (SPL) generated by the engine components and the aircraft, timeintegrated Effective Perceived Noise Levels (EPNL) in static as well as in-flight conditions can be estimated. As part of the TERA 2050 analysis, the global engine noise is predicted in terms of EPNL for a given flight path. This module will provide input to the operating cost model.

- Gaseous Emissions: to quantify on $\mathrm{NO}_{\mathrm{x}}$ emissions and to define a contrail prediction model allowing the assessment of the formation of persistent contrails. The gaseous emission models used will be based on either empirical/semi-empirical correlations, or will utilise 1D, physics based, stirred reactor combustor models as appropriate [30]. This module will provide input to the operating cost model.

- Operating cost: to assess direct operating costs for the ULTIMATE technologies as a function of fuel costs, time costs and environmental taxation costs. The influence of uncertainties in acquisition and maintenance cost will be addressed with the aid of sensitivity studies. Values of acquisition cost, maintenance cost and mission ranges for which the weighted average cost of capital (WACC) is greater than the internal rate of return (IRR) will be determined. These results will be used as the criteria to assess the economic viability of the ULTIMATE technologies [31].

- Policy: to incorporate a "policy scenario evaluation" model which will be used to assess the potential of the technologies to cope with evolutions of regulations such as changes in fuel price and hypothetical environmental taxation scenarios (ranging from "business as usual" to "progressive environmental awareness" to "high environmental awareness") [31].

- Optimizer: to allow design space exploration, parametric studies, sensitivity studies and trade-off studies as well as support for multidisciplinary and multi-objective analysis $[26,32]$.

\section{POTENTIAL FUEL BURN SAVING SCENARIO}

Along with the performance, weight and drag of the propulsion system, an energy level analysis of the complete aircraft and flight missions will provide a total picture of the environmental impact. ULTIMATE will work with a scenario based approach to show the potential of new technologies.

Figure 8 shows an early view of such a scenario, illustrating how ULTIMATE could contribute to global fleet $\mathrm{CO}_{2}$ reduction (green area). This scenario is based on that the traffic growth is $4.5 \%$ per annum until 2030 gradually slowing to $2 \%$, and the conservative assumption that introduction of ULTIMATE technologies into the fleet would start only at 2050 onwards. The 
graph shows that the $\mathrm{CO}_{2}$ reductions from improved operations and ATM and the improvements from projected aircraft and engine technologies will not by themselves be sufficient to stabilize fleet emissions. The ULTIMATE technologies are complementary to these projected developments and achieve substantial additional $\mathrm{CO}_{2}$ reductions.

This scenario is based on the assumption that conventional engine and airframe development will be able to continue targeted rates of improvements until 2050, that the current exponential growth of air traffic moderates, that ULTIMATE technologies are not available prior to 2050, but they are introduced progressively across the whole fleet in the next 25 years. They would then save over three billion tonnes of $\mathrm{CO}_{2}$ emissions in that period. However, faster traffic growth, a slower pace of reference technology development, or earlier phasing-in of selected ULTIMATE technologies would increase the overall savings. ULTIMATE will study such accelerated development scenarios.

Note that the ULTIMATE $\mathrm{CO}_{2}$ reductions will make it more likely that limited supplies of environmentally efficient biofuels would be sufficient to reach the overall ATAG goal of halving the current rate of net $\mathrm{CO}_{2}$ emissions.

\section{DISCUSSION AND CONCLUSION}

A categorization of disruptive engine technology has been introduced based on a lost work potential. This categorization allows a structured concept development of ultra-efficient aero engines. In association with this a number of radical technologies have been discussed.

To allow a rational down-selection of disruptive technology a simple partially quantitative metric has been proposed. Apart from allowing a quantitative measure to be available early in a research project, it also forces a project to exercise a number of interrelated disciplines preparing the ground for more advances mission analysis. This approach eases the transfer of models onto the evaluation platform.

Introducing radical technology into aero engines is always associated with balancing development risk against value provided to the customer. The complexity of the core technologies discussed requires propulsion architecture changes at least as challenging as the introduction of the turbofan engine in the late 1950s, but realising such concepts could unlock significant environmental and competitive benefits for the aviation industry.

\section{ACKNOWLEDGMENTS}

This work is financially supported by the E.U. under the "ULTIMATE - Ultra Low emission Technology Innovations for Mid-century Aircraft Turbine Engines" Project co-funded by the European Commission within the Horizon 2020 Programme (2014-2020) under the Grant Agreement n 633436.

\section{REFERENCES}

[1] European Commission, "G. Technology readiness levels (TRL)," HORIZON 2020 - WORK PROGRAMME
2014-2015 General Annexes, Extract from Part 19 Commission Decision C(2014)4995., [Online]. Available: http://ec.europa.eu/research/participants/data/ref/h2020/w p/2014_2015/annexes/h2020-wp1415-annex-gtrl_en.pdf. [Använd August 2015].

[2] "Annual Report of the Council," International Civil Aviation Organization, ICAO, 2012.

[3] B. Owen, "Fuel Efficiency Development and Prediction," Omega, 2008.

[4] IEA, "Key World Energy Statistics," International Energy Agency, 2014.

[5] T. Andres and B. Boden. [Online]. Available: http://cdiac.ornl.gov/ftp/ndp030/global.1751_2010.ems. [Accessed August 2015].

[6] "Global Carbon Atlas," [Online]. Available: http://www.globalcarbonatlas.org/?q=en/emissions. [Accessed August 2015].

[7] ACARE, "Realising Europe's vision for aviation, Strategic Research \& Innovation Agenda, Volume 1," Advisory Council for Aviation Research and Innovation in Europe, 2012.

[8] S. W. Ashcraft, A. S. Padron, K. A. Pascioni, G. W. Stout och D. L. Huff, "Review of Propulsion Technologies for N+3 Subsonic Vehicle Concepts," NASA/TM--2011217239, 2011.

[9] E. M. Greitzer, J. S. Hollman and W. K. Lord, N+3 Aircraft Concept Designs and Trade Studies, Volume I, 2010.

[10] T. Grönstedt, M. Irannezhad, L. Xu, O. Thulin and A. Lundbladh, "First and Second Law Analysis of Future Aircraft Engines," vol. 136, no. 3, 2014.

[11] S. Kaiser, A. Seitz, S. Donnerhack and A. Lundbladh, "A Composite Cycle Engine Concept with Hecto-Pressure Ratio," in Joint Propulsion Conference, Orlando, FL, USA, 2015.

[12] P. L. Meitner, M. Boruta and J. Jerovsek, "The Nutating Engine - Prototype Report and Test Results," NASA/TM-2006-214342, 2006.

[13] A. Perullo, D. N. Mavris and E. Fonseca, "An integrated assessment of an organic Rankine cycle concept for use in onboard aircraft power generation," in GT2013-95734, San Antonio, Texas, USA, 2013.

[14] R. Avellan, A. Capitao Patrao, A. Lundbladh och T. Grönstedt, "Preparing for Proof-of-Concept of a Novel Propeller for Open Rotor Engines," i ISABE-2015-22083, 2015.

[15] A. Lundbladh, L. Larsson and T. Grönstedt, "Transforming Propulsion Installation for Commercial Aircraft," in ISABE-2013-1434, Busan, Korea.

[16] "Napier Nomad - An Engine of Outstanding Efficiency," Flightglobal, 1954. [Online]. Available: 
http://www.flightglobal.com/pdfarchive/view/1954/1954 \%20-\%201201.html. [Accessed August 2015].

[17] S. Boggia and K. Rud, "Intercooled Recuperated Gas Turbine Engine Concept," in AIAA 2005-4192, 2005.

[18] K. Yakinthos, D. Missirlis, A. Sideridis, Z. Vlahostergios, O. Seite och A. Goulas, "Modelling Operation of System of Recuperative Heat Exchangers for Aero Engine with Combined use of Porosity Model and Thermo-Mechanical Model," Engineering Applications of Computational Fluid Mechanics, vol. 6, nr 4, pp. 608-621, 2012.

[19] R. Varvill och A. Bond, "The Skylon spaceplane: progress to realisation," Journal of the British Interplanetary Society, vol. 61, pp. 412-418, 2008.

[20] N. Yannakoulis, "Introducing Inter-Turbine Reheat in a High-Bypass Civil Turbofan Engine," MSc Thesis, Department of Power and Propulsion, Cranfield University, UK, Cranfield, 2004.

[21] S. Brunner, S. Baber, N. Harris, N. Caldwell, K. Keding, L. Rahrig och L. Pho, "and," NASA/CR-2010-216798, NASA N+3 Subsonic Fixed Wing Silent Efficient LowEmissions Commercial Transport.

[22] J. Wolkovitch, ""The joined wing-An overview."," Journal of Aircraft, vol. 23, no. 3, pp. 161-178., 1986.

[23] X. Zhao, O. Thulin och T. Grönstedt, "First and Second Law Analysis of Intercooled Turbofan Engine," i GT201543187, Montréal, Canada, 2015.

[24] ICCT, "International Civil Aviation Organization's CO2 Certification Requirement for new Aircraft," The International Council on Clean Transportation, 2013.

[25] V. Sethi, R. Camilleri, R. Singh, P. Pilidis, S. Ogaji och C. Celis, "Energy Plant Selection and Asset Management The TERA (Techno-Economic Enviromental Risk Analysis," i ISABE-2013-1429, 2013.

[26] K. Kyprianidis, "Multi-disciplinary Conceptual Design of Future Jet Engine Systems," PhD Thesis, School of Engineering, Cranfield University, 2010.

[27] V. Sethi, A. Nind, G. Doulgeris, P. Pilidis, M. Doussinault, P. Cobas och A. Rueda, "The map fitting tool methodology: gas turbine compressor off-design performance modeling," Journal of Turbomachinery, vol. 135, nr 6, 2013.

[28] T. Grönstedt, A. Dax, K. Kyprianidis och S. Ogaji, 'LowPressure System Component Advancements and its Influence on Future Turbofan Engine Emissions", , pp. 505-516,", i ASME Turbo Expo, GT2009-59950, Orlando, FL, USA, 2009.

[29] P. Lolis, S. Arumagam, V. Sethi och P. Pilidis , "New Empirical Aero Engine Gas Turbine Preliminary Weight Estimation Method Based On Artificial Neural Networks," i 71st SAWE Conference, Bad Goegging, 2012.
[30] B. Khandelwal, "Development of Gas Turbine Combustor Preliminary Design Methodologies and Preliminary Assessments of Advanced Low Emission Combustor Concepts," PhD Thesis, School of Engineering, Cranfield University, 2012.

[31] D. Nalianda, "Impact of Environmental Taxation Policies on Civil Aviation - A Techno-Economic Environmental Risk Assessment," PhD Thesis, School of Engineering, Cranfield University, , 2012.

[32] P. Bellocq, V. Sethi, A. Patin, S. Capodanno och F. Rodriguez, "Advanced 0-D Performance Modelling of Counter Rotating Propellers for Multi-Disciplinary Preliminary Design Assessments of Open Rotors," ASME TURBO EXPO 2014, GT-2014-27141, 2014.

\section{APPENDIX}

Key performance data of the year 2015 state of the art engine is found in Table 1 below. Corresponding calculations of lost work potential are found in Table 2.

TABLE 1. PERFORMANCE FOR YEAR 2015 ENGINE. ALL DATA IN CRUISE OPERATING POINT. GIVEN EFFICIENCIES ARE POLYTROPIC.

\begin{tabular}{|l|c|}
\hline Overall pressure ratio & 41.2 \\
\hline Bypass ratio & 13.3 \\
\hline Fan pressure ratio (outer stream) & 1.415 \\
\hline Fan pressure ratio (inner stream) & 1.274 \\
\hline Fan mass flow (kg/s) & 443.2 \\
\hline Fan efficiency (outer stream) & $91.8 \%$ \\
\hline $\begin{array}{l}\text { Intermediate pressure compressor } \\
\text { pressure ratio }\end{array}$ & 5.45 \\
\hline $\begin{array}{l}\text { Intermediate pressure compressor } \\
\text { efficiency }\end{array}$ & $91.5 \%$ \\
\hline $\begin{array}{l}\text { High pressure compressor pressure } \\
\text { ratio }\end{array}$ & 5.94 \\
\hline High pressure compressor efficiency & $92.1 \%$ \\
\hline High pressure turbine efficiency & $90.7 \%$ \\
\hline $\begin{array}{l}\text { Intermediate pressure turbine } \\
\text { efficiency }\end{array}$ & $91.0 \%$ \\
\hline Low pressure turbine efficiency & $91.3 \%$ \\
\hline SFC (mg/Ns) & 14.18 \\
\hline Cruise $\eta_{\text {thermal }}$ & $49.6 \%$ \\
\hline Cruise $\eta_{\text {propulsive }}$ & $.81 .6 \%$ \\
\hline
\end{tabular}

TABLE 2. CRUISE POINT EXERGY DESTRUCTION FOR YEAR 2015 ENGINE.

\begin{tabular}{|l|c|}
\hline Fan & $3.41 \%$ \\
\hline Compressors & $2.22 \%$ \\
\hline Bypass & $7.35 \%$ \\
\hline Turbines & $3.59 \%$ \\
\hline Core exhaust & $19.50 \%$ \\
\hline Burner & $22.47 \%$ \\
\hline
\end{tabular}

